\title{
Implementing the NHS information technology programme: qualitative study of progress in acute trusts
}

\author{
Jane Hendy, research fellow, ${ }^{1}$ Naomi Fulop, professor of health and health policy, ${ }^{2}$ Barnaby C Reeves, reader \\ in epidemiology, ${ }^{3}$ Andrew Hutchings, lecturer, ${ }^{4}$ Simon Collin research associate ${ }^{5}$
}

${ }^{1}$ Innovation Studies Centre, Imperial College, London SW7 2AZ

${ }^{2}$ School of Social Science and Public Policy, King's College, London

${ }^{3}$ Bristol Heart Institute, University of Bristol, Bristol

${ }^{4}$ Department of Public Health and Policy, London School of Hygiene and Tropical Medicine, London

${ }^{5}$ Department of Social Medicine, University of Bristol, Bristol

Correspondence to: J Hendy

j.hendy@imperial.ac.uk

doi: 10.1136/bmj.39195.598461.551

\section{ABSTRACT}

Objectives To describe progress and perceived challenges in implementing the NHS information and technology (IT) programme in England.

Design Case studies and in-depth interviews, with themes identified using a framework developed from grounded theory. We interviewed personnel who had been interviewed 18 months earlier, or new personnel in the same posts.

Setting Four NHS acute hospital trusts in England.

Participants Senior trust managers and clinicians, including chief executives, directors of IT, medical directors, and directors of nursing

Results Interviewees unreservedly supported the goals of the programme but had several serious concerns. As before, implementation is hampered by local financial deficits, delays in implementing patient administration systems that are compliant with the programme, and poor communication between Connecting for Health (the agency responsible for the programme) and local managers. New issues were raised. Local managers cannot prioritise implementing the programme because of competing financial priorities and uncertainties about the programme. They perceive a growing risk to patients' safety associated with delays and a loss of integration of components of the programme, and are discontented with Choose and Book (electronic booking for referrals from primary care).

Conclusions We recommend that the programme sets realistic timetables for individual trusts and advises managers about interim IT systems they have to purchase because of delays outside their control. Advice needs to be mindful of the need for trusts to ensure longer term compatibility with the programme and value for money. Trusts need assistance in prioritising modernisation of IT by, for example, including implementation of the programme in the performance management framework. Even with Connecting for Health adopting a different approach of setting central standards with local implementation, these issues will still need to be addressed. Lessons learnt in the NHS have wider relevance as healthcare systems, such as in France and Australia, look to realise the potential of large scale IT modernisation.

\section{INTRODUCTION}

The NHS information and technology (IT) programme is the largest civilian IT programme in the world. Connecting for Health is the agency responsible for delivering the programme. The main national features of the programme are a new networking service providing broadband, called "N3"; electronic booking, called Choose and Book; electronic transfer of prescriptions; and a nationally accessible summary of patients' records, called "the spine" (figure). With projected expenditure of over $£ 12 \mathrm{bn},{ }^{1}$ and in the face of professional concerns about maintaining patients' confidentiality, ${ }^{2}$ government ministers have accepted that elements such as the electronic record will be piloted rather than implemented across the board. ${ }^{3}$ In June 2006, the National Audit Office reported that the programme was facing important challenges in delivering systems to agreed timescales, ensuring involvement of NHS organisations in implementation, and gaining the support of NHS staff and the public. ${ }^{4}$ The National Audit Office reviewed a survey of NHS staff (including managers and clinical staff in NHS trusts) from July 2005 but did not examine the process of implementation in individual hospital trusts.

Since October 2003 we have been studying in detail the processes and outcomes of implementing the NHS IT programme in four acute hospital trusts in England. The study assesses the local context and progress made in each trust through in-depth interviews with staff over a two year period, alongside efficiency indicators derived from routine data. ${ }^{5}$ In August 2005 we reported findings from each trust's baseline assessment and information gathered from the first round of interviews, which took place between September and December $2004 .^{6}$ In this second phase, we re-interviewed the same senior trust staff or interviewed new personnel in the same posts, to revisit the issues previously raised, to describe how they may have changed, and to identify new issues that may have emerged.

\section{METHODS}

We met with key IT, finance, and clinical directorate staff, reviewed documents, and used routinely published data to collect baseline information. We also collected data from two stages of interviewing. Stage 1 interviews took place over two phases, firstly, between 
Box 1 Increased support for the overall goals of the NHS IT programme

"I still maintain it's the right thing to do. I think the principle, the principles, the philosophy, and the vision I think are absolutely sound. The challenge has been deliverability"-chief executive, trust 4

"Two years on I still believe in the concept, um, because I think the biggest single problem we have is sharing information between organisations and actually even within organisations, so the idea of having a single system or common systems as an IT concept only makes sense"-director of information management and technology, trust 4

"The consequences are, um, a complete re-think about the way that IT is introduced and it's needed it desperately... NHS IT programme is visionary, brilliant"-director of information management and technology, trust 2

September and December $2004^{6}$ and then again between January and April 2006. Stage 1 interviews concerned the implementation of the programme. Stage 2 interviews investigated how specific IT applications were experienced by staff and impacted on working practices (not reported here).

The data reported here are from the second phase of stage 1 interviews, with 25 senior NHS managers and clinicians in four acute trusts. To enhance generalisability, we selected four trusts that reflected a range of different organisational characteristics (table). We chose trusts that served both urban and more rural populations. The trusts differed in size, number of sites, performance indicators, financial situation, and the level of implementation of electronic functions. One site had a developed electronic system for patients' records, another site had not implemented any electronic functions, while the remaining two sites had small pockets of implemented electronic functions. ${ }^{6}$ Participants included all local senior management staff involved in implementing the programme. At each trust these included the chief executive, director of information management and technology, medical director, and director of nursing, all of whom have responsibility for both fiscal and clinical probity.

In the 18 months since the first study, there have been several changes in personnel; of the 23 staff originally interviewed in 2004 , only 11 were still in post in 2006 (two out of four chief executives, all four directors of nursing, two medical directors, and three directors of information technology). We analysed the views of the 11 staff interviewed in both phases of stage 1 separately from the views of the 14 staff interviewed only in the second phase to determine whether the views of the two groups of staff were substantially different.

An experienced qualitative researcher conducted semistructured interviews on a one to one basis at each trust. We developed the interview framework by drawing on literature concerned with the installation of computerised patients' records to identify key constructs. ${ }^{7-9}$ Topics discussed included the processes and outcomes of implementing electronic health systems and the impact of Connecting for Health policies and communications. Interviews were taped and transcribed.

We analysed the data in three stages based on grounded theory principles of coding and theme abstraction ${ }^{10}$ rather than strict adherence to the theory of Glaser and Strauss. ${ }^{11}$ Literature on organisational change suggests the context and processes of change will be multilayered and complex. ${ }^{12}$ Using the comparative case studies we explored this complexity by examining variations within and between the trusts, taking account of organisational changes relating to NHS policy and communications.

We then grouped emerging themes according to the "context" (each trust's characteristics) because "analysis of change needs to attend to the interplay between processes, people, and events both internal and external to the organisation."13

Building on our previous findings, we grouped themes around developing relations between each trust and other organisations involved in implementing the programme (including Connecting for Health and the local IT service providers). Two authors (JH and $\mathrm{NF}$ ) independently read the interview transcripts and agreed key themes.

\begin{tabular}{|c|c|c|c|c|}
\hline Characteristics of trusts in $2003 \mathrm{t}$ & hat took part in survey of & IS on implementation of & he new NHS I & \\
\hline & & Trus & & \\
\hline & 1 & 2 & 3 & 4 \\
\hline Size & Large & Large & Large & Small \\
\hline No of main sites & 2 (earlier merger) & 2 (earlier merger) & 1 & 1 \\
\hline Financial situation* & Moderate deficit $₫ £ 5 \mathrm{~m}$ & Small surplus & $\begin{array}{l}\text { Large deficit } \\
\ll £ 10 \mathrm{~m}\end{array}$ & Small deficit «£1m \\
\hline Performance indicators $†$ & 1 star & 2 stars & 0 star & 2 stars \\
\hline Electronic functions present & $\begin{array}{l}\text { None at site } 1 \text {; electronic } \\
\text { orders at site } 2\end{array}$ & $\begin{array}{l}\text { Electronic orders at both } \\
\text { sites; PACs }\end{array}$ & None & PACS \\
\hline Expected date for PAS replacementł & Unknown & 2007 & 2006 & $\begin{array}{l}2004-5 \text { "early adopter" of } \\
\text { electronic booking }\end{array}$ \\
\hline
\end{tabular}

PAS=patient administration system; PACS=picture archive and communication system.

*Annual accounts for 2002-3.

†Commission for Health Improvement (now called the Healthcare Commission) Clinical Governance Review 2002-3.

$\ddagger$ No patient administration systems were replaced during study (2003-6). 


\section{RESULTS}

Six main themes emerged from our earlier study ${ }^{6}$ :

- The impact of multiple sites resulting from recent mergers

- Poor communication between Connecting for Health and local managers

- The impact of financial deficits

- The need to prioritise performance targets

- Supporting existing "legacy" IT systems

- The delayed timetable for replacement patient administration systems.

Eighteen months later, three of the previous concerns are still apparent (financial deficits, poor communication, and continuing delay) and five new issues were raised:

- Increased support for the overall goals of the programme

- Continuing impact of financial deficits

- Managers distracted from implementing the programme by other priorities

- Continuing poor communication between Connecting for Health and local managers

- Continuing delay in replacing patient administration systems

- Growing risk to patient safety associated with delays

- Loss of integration of components of the programme

- Discontent with Choose and Book.

The eight themes are representative of all 25 staff interviewed. The issues raised were similar among staff interviewed in both phases of the research and those staff interviewed only in the second phase.

Increased support for the goals of the programme

Since the first round of interviews, we found that support for the concept underlying the programme had grown. The overriding view was that the NHS urgently needs the benefits that can be gained from IT modernisation implemented in a standardised way (box 1). We found little resistance to IT modernisation, with interviewees reporting that staff are ready, and

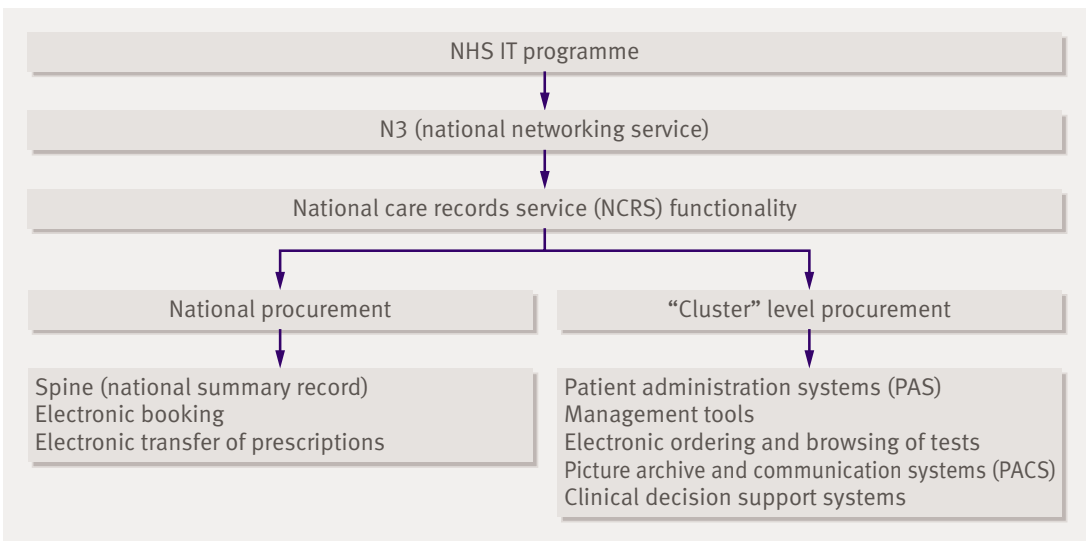

Outline of deliverables within the NHS IT programme
Box 2 More product placement and realisation of benefits

"We have to get some confidence back into the programme and that has to be about delivery because they can talk until the cows come home, but unless we see something happening on our own patch with a real clinical win to keep people on board"-director of information management and technology, trust 4

"I think one of the things that they haven't done very well is clarify some of the benefits they think that you're going to get out of it ... I haven't seen, you know, a good list of benefits ... I mean, you know, about between GPs and consultants, I mean actually things like managing a waiting list"-director of performance and improvement of information, trust 1

"I think the ... two big difficulties, the two big issues will be affordability, is it really going to deliver the benefits for the cost and is it, is it a cost pressure rather than an enabler of better efficiency across the organisation as a whole?... we are dependent on getting benefits out of it ... and I'm not confident at this stage, this stage that the system in operation will be so beneficial that it will really drive loads of things forward"--chief executive, trust 3

sometimes "desperate," for progress. Alongside this growing support, however, we also found concern about the ability of programme managers to deliver the programme. To maintain momentum, interviewees said that Connecting for Health needed to deliver products that work soon. They also emphasised the need for independent evaluation to measure the benefits and costs (box 2).

\section{Continuing impact of financial deficits}

In our earlier interviews, senior staff in trusts facing financial difficulties were concerned about how to pay for the implementation costs associated with IT modernisation. Currently, financial difficulties within the NHS are even more widespread, ${ }^{14}$ and this issue has become more important. Respondents reported that making savings is now more critical and that applications that are part of the programme are not the bargain they were expected to be. Implementation of picture archive and communication systems (PACS) is also causing disquiet. Some respondents reported that such applications supplied through the programme seem to be more expensive than market alternatives (box 3), but a central Connecting for Health mandate has left them with no choice but to implement the more expensive option.

Managers distracted from implementing the programme by other priorities

Financial deficits not only cause concern about how to pay for implementation of the programme but also act as distractions for managers. In the earlier interviews, some trust staff reported that recent mergers and the need to prioritise attainment of performance ratings made it difficult to prepare for the programme. Eighteen months later, the priority of trust finances 
Box 3 | Expensive solutions, especially PACS implementation

"A lot of the things are being sold to us at a much higher price than we would have been able to get if we'd been in a real market situation, so the total costs to the NHS have been very high indeed"-medical director, trust 4

"You know, we went out to procure a PACS system that was not part of the national programme, and, you know, got told we couldn't do it. That's resulted in more, a lot more expenditure for the trust than the local solution, so I think that then heaps another layer of problems on ... where we have a deficit to be forced down a route that's more expensive without financial support that really we should be getting about that, you know, it's just another disincentive really"-chief executive, trust 2 "It's certainly extensive costs, and it's compulsory acquisition, we have to have it in by March, that's it. So, it's, it's just a cost pressure, it's another, another one of many cost pressures at the trust"-head of system delivery,trust 1

dominated. Two of our four trusts have had "turnaround teams" in place (external consultants brought in to help trusts resolve financial crises). One trust also has the Department of Health's performance support team working with it. The dominant and immediate need to eliminate any overspend, while maintaining performance, seems to leave managers little time to commit to implementing the programme or any other new services or products (box 4). The programme was reported to be a pressing priority only in trusts where managers perceived a considerable risk to patients' safety from having to maintain existing legacy systems while waiting for new systems to arrive (see box 8$)$.

\section{Poor communication between Connecting for Health and} local managers

Previously, interviewees in all four trusts were concerned with a lack of clarity from Connecting for Health about the timetable for implementation. Eighteen months later, although respondents were enthusiastic about the goals of the programme, the perception of poor communication was unchanged. There is still uncertainty about the timetable for

\section{Box 4 Managers distracted from implementing the NHS IT programme by other} priorities

"Actually motivating people in this particular trust at this particular time to have the vision to get involved in a nationwide project, which isn't delivery, is virtually impossible. The majority of my colleagues are surviving day to day with no beds, cuts... There are real immediate issues, there isn't the luxury, I suppose, of people having the time and the intellectual capacity to pursue a 10 year vision. We try to, we're trying to survive"-medical director, trust 2

"I would like to see good IT systems within the NHS ... where I'm coming from in a trust that's got the performance support team in and we've got the turnaround team in, we are trying to pull out a great deal of expenditure, about $10 \%$ of our budget ... it does feel a little unreal trying to implement a large IT system on top of that ... there's no real plans yet because we haven't got that far. And, to be honest, the whole other agenda [making savings] is just taking my time up"-director of nursing, trust 1 delivery of key components of the programme (such as core hospital administration systems compliant with the hardware and software applications that will make up the programme) and about the extent of financial assistance for "required" components. Respondents reported that much of the decision making has been between Connecting for Health and the local IT service provider. This lack of local involvement seems to have increased feelings of disempowerment and frustration (box 5). The uncertainty has also resulted in some trusts adopting policies that actively discourage staff from engaging with the programme (box 6).

\section{Continuing delay in replacing patient administration} systems (PAS)

In the first interviews, respondents were concerned about when their patient administration systems (PAS) would be replaced. Originally, the national programme planned for this system to be installed before any clinical applications. Because of delays in developing a PAS that can achieve connectivity with the "spine" (a nationally accessible summary of patients' records $)^{15}$ this plan has had to be revised and interim off the shelf applications are now being offered. The revised plan has slowed progress, and trusts are still unsure when their replacement PAS will be implemented. Interim applications will allow trusts to move forward to some extent but will not achieve the promised wider connectivity with other NHS hospital trusts and primary care teams (box 7).

Growing risk to patients' safety associated with delays

Before the programme was conceived, NHS hospitals bought their own IT systems. When first interviewed,

\section{Box 5 Continued uncertainty and feeling of disempowerment}

"The frustration is we're not the customers, as far as the suppliers are concerned ... CfH pull the strings, it's their contract, we're just the entity that takes the solution"director of information management and technology, trust 2

"The communication has been bloody awful really... we've kind of been the recipients of those relationships as opposed to being directly as influential as we would like to be in those relationships. No, so all I'm saying is every two months we say 'Where's my pathology system?' 'Oh, well, we've got to finish this ...' so you kind of tune out, that's how it has felt, you've felt a little bit I guess disempowered really, um, because, you don't have the internal levers to actually, most problems I've got I can sort out a lot, but I feel it's not within my power to sort them out"-chief executive, trust 4

"It's all been about contractual things, so ourselves kind of at the bottom of the food chain we just, we don't get involved in any of this and it has been two and a half years, it seems to be solid negotiation and renegotiation between NHS IT programme and BT"director of information management and technology, trust 4 


\section{Box 6 | Lack of clinician engagement}

"I'm not driving the national programme forward at all . . . We're not doing any enabling at all as far as that process is concerned. I'm definitely not going to do what some of my colleagues have and that's work on the basis that they were getting their slots and have ended up with staff employed, ready to go and nothing to go with"-director of information management and technology, trust 2

"We've actively discouraged it here [engagement], which is a strange thing to do, in a way, but because we didn't want to raise expectations ... there is no software backing that up at the moment, or not that we've seen ... I don't encourage our clinicians to get involved on the demonstration days"--director of information management and technology, trust 4

“I wouldn't go out and sell it to people because I don't know when it's going to arrive .. . getting people too enthusiastic on specific timescales would have been very

dangerous"-chief executive, trust 4

"I think the biggest problem we've had, as an organisation, is, um, you have to have a product to sell to the clinical staff to get them enthused, to get them to use it, and the biggest problem we've had is that the product has not revealed itself to us yet"medical director, trust 3
Choose and Book (patients being able to choose to be referred to one of a range of hospitals) among the staff we interviewed (box 10). The technical problems affecting electronic booking have also undermined confidence in other planned applications. None of the managers or clinicians we interviewed was optimistic about the ability of Connecting for Health to deliver the systems. The doubts expressed were twofold: whether it was technically possible and whether the products would be delivered in a reasonable time frame. Participants expressed feelings of frustration at the slow progress.

\section{DISCUSSION}

Key findings

Over three years from inception, and despite several setbacks and some hostile media coverage, ${ }^{17}$ the government's NHS IT programme remains an objective that many NHS staff support. In line with the National Audit Office report ${ }^{4}$ all of our interviewees were enthusiastic about the goals of the programme.

Set against this support were concerns about a lack of clarity and progress. Senior managers need to make financial savings and achieve efficiencies. Although modernisation of IT should facilitate these goals, continuing uncertainty makes key managerial decisions more rather than less difficult. Trusts still do not know what the local costs of implementation will be; when a replacement patient administration system compliant with the programme will be available; the timetable for delivery of interim applications; the features of these applications; and the likely benefits and study are still waiting for new systems. Where replace ment systems were needed in 2002, the delay is now perceived to represent an unacceptable risk to patients' safety, with trusts considering buying interim systems outside the programme (box 8 ).

\section{Loss of integration of components of the programme}

The original goal of access to information across the NHS that underpinned the IT programme seems to have been lost. ${ }^{16}$ The lack of integration offered by interim applications has left senior trust staff questioning whether NHS-wide connectivity will ever be achieved and why trusts have had to wait several years for the new systems. The purchase of interim applications does not seem far removed from how the NHS acquired IT before the programme, with the problems of this approach seemingly perpetuated, such as databases that cannot be accessed from outside the trust (box 9). Managers also questioned how the government vision of decentralising clinical services, by increasing provision in the private sector, aligns with a centralised approach to information sharing (box 9).

\section{Discontent with Choose and Book}

Since the first round of interviews, acute trusts and local primary care teams have proceeded with implementation of Choose and Book, a system that allows general practitioners to make patients' appointments and referrals into acute trusts electronically. We found little support for the patients' choice element of

\section{Box $7 \mid$ Continued delays and re-planning}

"The dates keep getting re-planned because we're not allowed to say delayed anymore. We joke in this trust that the NHS IT programme is never closer than two years away and just when you think it's actually going to be closer it suddenly goes again and it's two years away again"-systems training manager, trust 3

"I see all the sort of stuff, the propaganda that comes out from $\mathrm{CfH}$ and they're always saying how a lot of these things are actually on time, despite what the press says, hundreds of people are using the new systems and all that sort of, and I must say, you know, there's not an awful lot of evidence of that across the country, I don't think"-clinician lead for Connecting for Health, trust 2

"They obviously, they know that the CRS [Care Records Service] isn't going to deliver in a sort of timely manner, so they're kind of looking at this other product to work with existing PASs"-assistant director of information management and technology, trust 4

"So we've got these tactical solutions coming in and that helps because we're seen to be moving forward. My only problem with tactical solutions is that in a few year's time one expects that tactical solutions to be replaced with whatever IDX [one of the specialist subcontractors] is going to demand and I don't know that I really want to put my trust through implementing a tactical PAS and then doing it again"-director of information management and technology, trust 2 
efficiencies from new systems (whether interim or planned).

Ministers and senior civil servants have acknowledged that the total cost of the programme will far exceed the current budget of $£ 6.2 \mathrm{bn}$ but have not clarified how the additional costs will be met. ${ }^{18}$ It is not clear how much more implementation and additional "required components" will cost trusts, nor what cost savings might be expected after implementation. Trusts have also not received guidance on how to maximise possible savings by, for example, redesigning local work practices. ${ }^{4}$

It has been difficult for trusts to prioritise the programme and engage staff when implementation timetables keep shifting. In the meantime, trusts have used a "patch and mend" approach to maintain existing systems. Major concerns over the risk to patients' safety by continuing this approach have been expressed and reported elsewhere. ${ }^{19}$ Trusts are attempting to mitigate the risk by opting for interim systems, although delivery of these interim systems is also delayed. ${ }^{20}$ Purchasing interim systems outside the programme is also likely to be inefficient if trusts subsequently have to buy new systems compliant with the programme during the lifetime of the interim system.

\section{The programme in wider context}

Although the diversity of healthcare provision in other countries means projects on the huge scale of the national programme for information technology are unlikely, the widespread implementation of electronic healthcare records is progressing elsewhere..$^{21}$ France has a national electronic medical patients' record system planned for introduction in 2007, combining all consultations and procedures, treatments, drugs, and medical devices prescribed. Similarly, Australia is trialling a new national management system for electronic patients'

\section{Box $8 \mid$ Concern over growing risk to patients' safety; some trusts may go it alone}

"Our path system is extremely out of date, it's not just obsolescent, it's obsolete. When we had to buy some new bits for it recently we had to buy them through eBay from someone in America because there's just no bits in this country, so it's a huge risk to the trust that we're still carrying this path system"-medical director, trust 4

"It's been urgent that it's replaced all the time l've been here, which is about three and a half years, so I mean the first thing I heard about when I arrived was the fact that the PAS system needed to be replaced. It is a clinical risk"-director of nursing, trust 1 "And there are a number of risks that are associated with our old system, some very serious risks and risks in development and progress within the organisation and between the organisations due to this lack of putting a good idea into practice"divisional manager for diagnostic therapies and outpatients, trust 4

"Well that's a risk we, that is a risk. I mean it could, you know, die tomorrow, it's such an old system and then we are really stuffed, basically"-director of nursing, trust 2

"People are saying 'Thank God we're going to get a new system that will replace this load of old, you know, cobblers' ... Americans use the expression 'You need a burning platform to get change.' Well, I think from an IT perspective we've probably got one"director of information management and technology, trust 2

"One of the options I have is to say 'To hell with it, l'll just go and buy one.' Well, that's a kind of tricky decision and that's the decision some of my peers are making elsewhere, they're saying 'Well, sod that, I'll go elsewhere' "- divisional manager for diagnostic therapies and outpatients, trust 4
Box 9 Loss of integration of components of the NHS IT programme

"I think it is back-peddling big time because I don't think the, right now they're in a position to deliver that original vision and so even things like the PACS was going to be an NHS-wide archive and then it was going to be a cluster archive and now they're just talking about having a trust archive"-director of information management and technology, trust 4

"I'm just worried that the ideas are actually drifting away from the way that initial strategy, from the way the trust is working, whereas at one time you kind of offered a nice way forward I'm worried it's kind of diverging"divisional manager for diagnostic therapies and outpatients, trust 4

"One of the things that's become apparent is that the original vision of a shared record between primary and secondary care is not at the moment on the, on the design, aim and design ... what they're looking to do is to use messaging systems between primary and secondary care, so effectively you'll have electronic letters and discharge summaries and those sorts of reports ... and the spine won't, the spine is currently going to be quite thin, so it's not going to be data rich"clinician lead for Connecting for Health, trust 2

"We've got foundation trusts, we've got perhaps more importantly the mixed economy so, are we saying that a condition of a private provider receiving NHS work is that they have to be signed up to the national programme? ... We're not going to have a national solution that actually is fit for purpose in a mixed economy and providers"-chief executive, trust 2

"I genuinely am not sure whether the solutions are solutions to yesterday's analysis rather than today's analysis ... I think what's happened over the last few years is we have moved from NHS plc to healthcare, as an industry, which has lots of different players in it"chief executive, trust 3

medical records, called HealthConnect. ${ }^{21}$ Creation of the Office of the National Coordinator for Health Information Technology in the United States also indicates a strong commitment from the current US administration to this task. ${ }^{22}$

For these countries, an important lesson to emerge from our study is the difficulty in achieving an appropriate balance of responsibility between government and local healthcare organisations. Devolving control of IT to local managers can result in a lack of standards and disparate functionality. Central control is equally problematic. The national programme covers the entire NHS in England. The sheer size of the task has made progress slow. Effective communication and a shared commitment to the task across all health sectors have been difficult.

Implementation of Choose and Book illustrates these difficulties. There was no integration of IT systems in trusts and general practices and acute trust staff were unable to reconcile timetables for implementation and goals for Choose and Book with their primary care colleagues. Although general practitioners derive substantial benefits from using IT systems for 


\section{WHAT IS ALREADY KNOWN ON THIS TOPIC}

Concerns have been raised in the national media and elsewhere about the implementation of the NHS IT programme

Last year's National Audit Office report stated that, while the NHS IT programme has made substantial progress, challenges lie ahead, including delivering systems within agreed

timetables, ensuring that NHS organisations fully play their part, and winning the support of NHS staff

\section{WHAT THIS STUDY ADDS}

Senior trust managers and clinicians reported concerns about a growing risk to patients safety from continuing delays in delivering new IT systems; the cost of interim applications and whether they represent value for money; uncertainty over delivery timetables; and achieving integrated IT systems, as the NHS IT programme original envisaged

Several of these concerns had actually been first expressed over two years ago

Acute hospital trusts cannot prioritise the implementation of the NHS IT programme because of these uncertainties and their need to achieve stringent financial targets

the day to day running of their practices, these systems have been specifically designed to meet their business needs. The systems underpin relatively simple clinical functions, ${ }^{23}$ but effectively allow general practitioners to run their practices. They may perceive that they have little to gain from this programme and, importantly, can choose not to have applications of the programme imposed on them. ${ }^{24}$

By contrast, acute hospital trusts have to deal with more urgent and complex demands, requiring fast communication between hundreds of people across many specialties and professional disciplines, yet the IT systems to support this activity are poor. Acute hospitals stand to benefit hugely from modernisation, not least in achieving the efficiencies currently demanded of them. For managers and clinicians in acute trusts, the programme is desperately needed and has to work. Independent procurement of IT systems, in the

\section{Box 10 | Discontent with Choose and Book and loss of confidence in the programme}

"I've not really talked to the clinicians about, about whether they think it's a good idea or not [Care Records Service]. They certainly think Choose and Book is a crap idea, they hate it"- director of performance and improvement of information, trust 1

"We'll call it Choose and Book because it helps with politics. The software is not fit for purpose ... We have an unstable middle-ware server because the spine keeps vanishing ... what happens is the synchronisation messages from them to the other doesn't happen, things get lost, so you end up with patients booked, but we don't know about them ... We're getting a 53 , sorry $57 \%$ error rate at the moment"-director of information management and technology, trust 2

“Technically l'm not sure that they can deliver it at the moment ... I don't think they have the architecture in place to actually deliver it on a national scale, let alone, actually even a cluster scale, to be honest, so I think they are struggling with it"director of information management and technology, trust 4

"Somebody, not here but at the PCT level, is trying to increase that all the time [usage by general practitioners] ... I know that some GPs absolutely hate it and I get the impression that they're using it under duress and that the slightest fault is a case of 'Well, what a rubbish system, would never work anyway' "-chief executive, trust 4

"If it doesn't start delivering soon people will begin to say it can't deliver ... they, they just feel resentment or that it's irrelevant or, worse still, it looks like money poured down the drain while they're having to make staff redundant ... then there will gradually be a sort of almost a 'We're going to make sure it doesn't work' mentality coming"-chief executive, trust 4 absence of national standards, has already been tried with little success. ${ }^{25}$

These difficulties have led to a third, middle way, being tried: setting central standards but with local implementation. As recommended by the British Computer Society, ${ }^{26}$ the role Connecting for Health is now shifting away from implementation towards providing a national infrastructure and setting standards. Implementation will now be devolved more locally, as set out in the NHS national business plan for 2007-8. ${ }^{27}$ Even with these changes, the issues raised in our study, particularly in regard to risks to patients' safety, still need to be urgently addressed.

\section{Strengths and limitations of the study}

The small number of participating trusts makes us cautious about generalising our findings. The trusts studied are in only two of the five geographic implementation clusters. Uncertainty over timetables and a lack of progress, however, have been widely reported everywhere. ${ }^{28}$ Moreover, mergers of IT companies also means that the trusts studied are being supplied by two of (now) four local service providers. ${ }^{28}$

Concerns raised by respondents about performance and finance are prevalent issues in the NHS but may be more salient in our participating trusts than nationally. We found no substantive differences in views among staff interviewed in the earlier phase of the study and those interviewed later. Staff interviewed were all senior NHS personnel. The 14 recent employees would probably have been recruited from similar NHS posts elsewhere, suggesting wider generalisability. Another limitation of our study is the lack of a primary care perspective, which we have discussed above.

Set against these limitations, ours is the only indepth, longitudinal study of modernisation of IT within the NHS. We interviewed a cross section of senior trust staff responsible for implementing the programme in NHS hospitals over a period of two years. These interviews have provided us with a detailed account of their views about progress, the challenges they perceive in implementing the programme in NHS hospitals, and their information needs in addressing these challenges.

\section{Conclusions}

The staff we interviewed were unreservedly in favour of IT modernisation, but this support will quickly diminish unless more progress is achieved. To progress and maintain a vision consistent with the original goals of the programme, Connecting for Health needs to address the uncertainty experienced by trusts and take responsibility for advising about interim decisions. Trust managers urgently need concrete information about implementation timetables, long term goals of the programme, and value for money. Finally, trusts need help to prioritise IT modernisation against other competing financial pressures-for example, by including it in performance management frameworks. 
We thank participating trusts, individual interviewees for their time and interest, and members of the steering group for their continuing support.

Contributors: $\mathrm{JH}$ took part in conducting, planning, and reporting the work. NF took part in planning and reporting and is guarantor. BCR and AH took part in planning and reporting. SC took part in conducting and reporting. Funding: NHS Service Delivery and Organisation R\&D Programme (ref. SDO/ 44/2003).

Competing interests: None declared.

Ethical approval: NHS Trent multicentre research ethics committee and NHS trust local research ethics committees.

1 House of Commons. Committee of Public Accounts. Department of Health. The National Programme for IT in the NHS. Twentieth report of session 2006-7. Report, together with formal minutes oral and written evidence. March 2007. www.publications.parliament.uk/pa/ cm200607/cmselect/cmpubacc/390/390.pdf.

2 GPs and their families urged to boycott NHS "spine." $e$-health-insider 2006;230. www.e-health-insider.com/.

3 Care records now running 2.5 years late. e-health-insider 2006;227. www.e-health-insider.com/.

4 National Audit Office. Department of Health: the National Programme for IT in the NHS. London: Stationery Office, 2006

5 Department of Health. The efficiency map. www.dh.gov.uk/ assetRoot/04/11/75/50/04117550.pdf.

6 Hendy J, Reeves BC, Fulop N, Hutchings A, Masseria C. Challenges to the national programme for information technology (NHS IT programme): a qualitative study. BMJ 2005:331:331-4.

7 Jones AJ, Hart A, Henwood F, Gerhardt C. The use of electronic patien records (EPRS) in the maternity services: professional and public acceptability. Brighton: University of Brighton, 2003:1-14.

8 Ash JS, Stavri PZ, Kuperman GJ. A consensus statement on considerations for a successful CPOE implementation. J Am Med Inform Assoc 2003;10:229-34.

9 Berg M. Implementing information systems in health care organizations: myths and challenges. Int I Med Inform 2001;64:143-56.

10 Miles MB. Qualitative data as an attractive nuisance- the problem of analysis. Adm Sci Q 1979;24:590-601.

11 Glaser BG, Strauss AL. The discovery of grounded theory: strategies for qualitative research. New York: Aldine de Gruyter, 1967

12 Pettigrew A. The management of strategic change. Oxford: Blackwell, 1987.
13 McNulty T, Ferlie E. Re-engineering health care: the complexities of organisational transformation. Oxford: Oxford University Press, 2002.

14 Day M. NHS faces job cuts as financial crisis deepens. BMJ 2006;332:743.

15 Cross M. Keeping the NHS electronic spine on track. BM 2006;332:656-8.

16 Connecting for heath: brakes placed on electronic care record as concerns grow. Health Serv J 2006;4 May:6.

17 Independent audit could be key to success. Computer Weekly 2006;11 April;18.

18 NHS IT programme scrutinised by public accounts committee. ehealth-insider. 2006;231. www.e-health-insider.com/.

19 Major incidents hit NHS national systems. Computer Weekly 2006:19 Sept. www.computerweekly.com/Articles/2006/09/19/ 218552/major-incidents-hit-nhs-national-systems. htm\#ContentContinues.

20 Lengthy delivery for NHS IT programme maternity systems. e-healthinsider. 2006;231. www.e-health-insider.com/.

21 Ettelt S, Nolte E, Mays N, Thomson S, McKee M, the International Healthcare Comparisons Network. Health care outside hospital: accessing generalist and specialist care in eight countries. Copenhagen: European Observatory on Health Systems and Policies, 2006. www.euro.who.int/Document/E89259.pdf.

22 Iglehart JK. Pursuing health IT: the delicate dance of government and the market. Health Affairs 2005;24:1100-1.

23 Benson T. Why general practitioners use computers and hospital doctors do not-part 2: scalability. BMI 2002;325:1090-3.

24 Keen J. The NHS programme for information technology. This massive natural experiment needs evaluating and regulating. $B M$ J 2006;333:3-4

25 Jones M. Learning the lessons of history? Electronic records in the United Kingdom acute hospitals, 1988-2002. Health Inform J 2004;10:253-63.

26 Collins T. British Computer Society report. www.computerweekly. com/Articles/2006/08/29/218056/central-nhs-it-may-not-workwarns-bcs.htm.

27 Department of Health. The NHS in England: the operating framework for 2007/08. www.dh.gov.uk/en/Publicationsandstatistics/ Publications/PublicationsPolicyAndGuidance/DH 063267.

$28 \mathrm{CfH}$ aims to install at 22 acute trusts by October. $e$-health-insider 2006;232. www.e-health-insider.com/.

Accepted: 17 April 2007 